University of Nebraska - Lincoln

DigitalCommons@University of Nebraska - Lincoln

Faculty Publications from the Department of Electrical \& Computer Engineering, Department Electrical and Computer Engineering

2011

\title{
Computational Intelligence for Control of Wind Turbine Generators
}

Wei Qiao

University of Nebraska-Lincoln, wqiao@engr.unl.edu

Jiaqi Liang

Georgia Institute of Technology, jliang@gatech.edu

Ganesh K. Venayagamoorthy

Missouri University of Science and Technology, gkumar@ieee.org

Ronald Harley

University of KwaZulu-Natal, Durban, rharley@ieee.org

Follow this and additional works at: https://digitalcommons.unl.edu/electricalengineeringfacpub

Part of the Electrical and Computer Engineering Commons

Qiao, Wei; Liang, Jiaqi; Venayagamoorthy, Ganesh K.; and Harley, Ronald, "Computational Intelligence for Control of Wind Turbine Generators" (2011). Faculty Publications from the Department of Electrical and Computer Engineering. 217.

https://digitalcommons.unl.edu/electricalengineeringfacpub/217

This Article is brought to you for free and open access by the Electrical \& Computer Engineering, Department of at DigitalCommons@University of Nebraska - Lincoln. It has been accepted for inclusion in Faculty Publications from the Department of Electrical and Computer Engineering by an authorized administrator of DigitalCommons@University of Nebraska - Lincoln. 


\title{
Computational Intelligence for Control of Wind Turbine Generators
}

\author{
Wei Qiao, Member, IEEE, Jiaqi Liang, Student Member, IEEE, Ganesh K. Venayagamoorthy, Senior \\ Member, IEEE, Ronald Harley, Fellow, IEEE
}

\begin{abstract}
This paper summarizes past and ongoing research in the area of the application of computational intelligence (CI) for control of wind turbine generators (WTGs). Several intelligent design approaches and control strategies, including optimal design of WTG controllers using particle swarm optimization (PSO) and mean-variance optimization (MVO) algorithms and adaptive critic design-based coordinated optimal adaptive control for wind plants and shunt FACTS devices, are presented for dynamic performance and fault ride-through enhancement of WTGs and the associated power grid. The effectiveness of these intelligent design approaches and control strategies are demonstrated by nonreal- and real-time simulations in PSCAD/EMTDC and RSCAD/RTDS, respectively.
\end{abstract}

Index Terms--Computational intelligence (CI), doubly fed induction generator (DFIG), dual heuristic programming (DHP), FACTS device, heuristic dynamic programming (HDP), particle swarm optimization (PSO), radial basis function neural network (RBFNN), wind turbine.

\section{INTRODUCTION}

$\mathrm{D}$ URING the last decade, there has been a worldwide rapid growth in the exploitation of wind energy. To better integrate this type of clean and renewable energy, much research effort has gone into the issues of control of wind turbine generator (WTG) systems. Different computational intelligence (CI) techniques, including particle swarm optimization (PSO), mean-variance optimization (MVO), fuzzy logics, neural networks, etc., have been applied to address challenging control issues (both transient dynamic and steady-state control) in WTG systems.

Most existing wind farms and those in planning employ the variable-speed wind turbines with either doubly-fed induction

The authors are members of the Task Force on Intelligent Control of Wind Plants, which is part of the Intelligent Control Systems Working Group of the Intelligent Systems Subcommittee, under the Power Systems Analysis, Computing and Economics Committee of the IEEE Power \& Energy Society.

W. Qiao is with the Department of Electrical Engineering, University of Nebraska-Lincoln, Lincoln, NE 68588-0511 USA (e-mail: wqiao@engr.unl.edu).

J. Liang is with the School of Electrical and Computer Engineering, Georgia Institute of Technology, Atlanta, GA 30332 USA (e-mail: jliang@gatech.edu).

G. K. Venayagamoorthy is with the Real-Time Power and Intelligent Systems Laboratory, Missouri University of Science and Technology, Rolla, MO 65409, USA (e-mail: gkumar@ieee.org).

R. G. Harley is with the School of Electrical and Computer Engineering, Georgia Institute of Technology, Atlanta, GA 30332 USA. He is also Professor Emeritus and Honorary Research Associate, University of KwaZulu-Natal, Durban, South Africa (e-mail: rharley@ieee.org). generators (DFIGs) with partially-rated power electronic converters (PECs) or synchronous generators with fully-rated PECs. Control of WTGs is achieved by controlling the PECs using a set of PI controllers. Tuning these PI controllers is tedious and it is difficult to obtain the optimal parameters due to the nonlinearity and the high complexity of the system.

Many WTGs are installed in remote, rural areas, which usually have electrically weak power grids, characterized by low short circuit ratios and under-voltage conditions. The successful integration of WTGs into some weak power grids will require dedicated local shunt FACTS devices [1], e.g., the STATCOM, to provide fast and smooth controllable reactive compensation and voltage support [2]. On the other hand, the WTGs can also be used to provide limited reactive power control, which reduces the demands of dynamic reactive compensation from the local FACTS devices. In order to achieve certain operational and economical benefits, it is necessary to coordinate the control actions of the WTGs and local FACTS devices so that the WTGs will behave like other traditional sources of generation to assist in maintaining grid voltage and frequency stability, particularly during transient conditions.

For WTGs to capture maximum wind power, it is necessary to have an effective maximum power point tracking (MPPT) control algorithm. Traditional MPPT schemes require the wind speed and turbine rotating speed as inputs. To achieve wind speed sensorless control, neural networks [3]-[7] and the Takagi-Sugeno-Kang fuzzy model [8] were designed to implement an inverse mapping of the WTG system and provide wind speed estimations. Others used hill-climb methods [9], [10] and fuzzy logic controllers [11], [12] to perform online searching of the maximum power point. In particular, the MPPT control schemes in [5] and [6] were designed for DFIG wind turbines and direct-drive permanentmagnet synchronous generator wind turbines, respectively, without the need for both wind speed and turbine/generator shaft speed measurements.

A higher-level WTG control involves providing frequencydroop characteristics and frequency regulation reserve to the power grids. A fuzzy logic controller was designed to coordinate the turbine pitch angle and the generator speed to provide primary frequency reserve for grid frequency deviation [13].

This paper presents several CI techniques to enhance the control and operating performance of grid-connected DFIGs wind turbines. First, two heuristics optimization approaches, 
namely particle swarm optimization and mean-variance optimization (MVO), are presented for the optimal design of PI controllers for the rotor-side PWM converter (RSC) of a DFIG [14]. Next, a nonlinear optimal adaptive interface neurocontroller (INC) [15] is presented for the coordinated reactive power control of a large wind farm and a STATCOM, which is connected to the point of connection between the wind farm and the utility network. The heuristic dynamic programming (HDP) method and radial basis function neural networks (RBFNNs) are used to design the INC. It enhances the fault ride-through capability of the wind farm and improves post-fault power oscillation damping of the power system. The proposed intelligent design approaches and control strategies are validated by nonreal- and real-time simulation studies in PSCAD/EMTDC and RSCAD/RTDS respectively.

\section{DFIG WIND TURBINE}

The basic configuration of a DFIG wind turbine is shown in Fig. 1. The wound-rotor induction machine is fed from both stator and rotor sides. The stator is directly connected to the grid while the rotor is fed through a partial-rated variablefrequency converter (VFC). It consists of two four-quadrant IGBT PWM converters, a RSC and a grid-side converter (GSC), connected back-to-back by a dc-link capacitor.

Control of the DFIG is achieved by control of the VFC, which includes control of the RSC and control of the GSC [16]. The RSC control scheme (Fig. 2) is expected to achieve the following objectives: 1) regulating the DFIG rotor speed for maximum wind power generation, 2) controlling the stator-side reactive power of the DFIG. The objective of the GSC control scheme is to keep the dc-link voltage constant regardless of the magnitude and direction of the rotor power. The GSC control scheme can also be arranged to regulate the reactive power exchanged between the GSC and the grid.

\section{Computational Intelligence TeChNiQues}

Computational intelligence (CI) is the study of adaptive mechanisms to enable or facilitate intelligent behavior in complex and changing environments. These mechanisms exhibit an ability to learn or adapt to new situations, to generalize abstract, discover and associate. There are five main CI paradigms, which are artificial neural networks, artificial immune systems, fuzzy systems, evolutionary computation, and swarm intelligence [17], [22]. This section

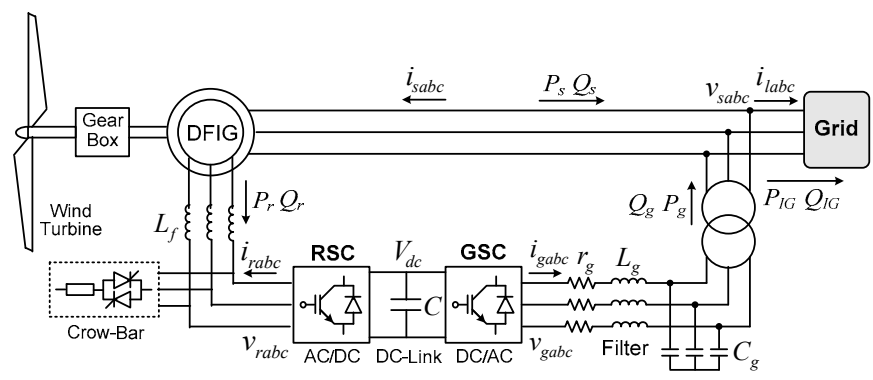

Fig. 1. Configuration of a DFIG wind turbine.

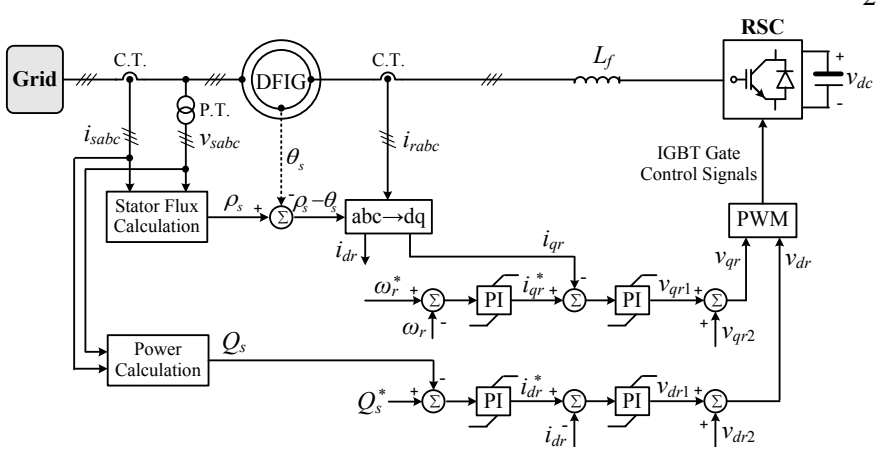

Fig. 2. Overall vector control scheme of the RSC.

briefly describes several computational intelligence techniques presented in this paper.

\section{A. Particle Swarm Optimization (PSO)}

PSO [18] is a population based stochastic optimization technique. It searches for the optimal solution from a population of moving particles, based on a fitness or performance measure function. Each particle represents a potential solution and has a position (vector $x_{i}$ ) and a velocity (vector $v_{i}$ ) in the problem space. Each particle keeps track of its individual best position $x_{i, p b e s t}$, which is associated with the best fitness it has achieved so far, at any step in the solution. Moreover, the best position among all the particles obtained so far in the swarm is kept track of as $x_{\text {gbest }}$. This information is shared by all particles. At each time step $k$, a new velocity for particle $i(i=1,2, \cdots, N)$ is updated by:

$$
v_{i}(k+1)=w \cdot v_{i}(k)+c_{1} \phi_{1}\left(x_{i, p b e s t}(k)-x_{i}(k)\right)+c_{2} \phi_{2}\left(x_{\text {gbest }}(k)-x_{i}(k)\right)
$$

where $c_{1}$ and $c_{2}$ are positive constants representing the weighting of the acceleration terms that guide each particle toward the individual best and the swarm best positions $x_{i, p b e s t}$ and $x_{g b e s t}$, respectively; $\phi_{1}$ and $\phi_{2}$ are uniformly distributed random numbers in $[0,1] ; w$ is a positive inertia weight that controls a particle's exploration and exploitation capabilities during a search; $N$ is the number of particles in the swarm. Based on the updated velocity, each particle changes its position according to the following equation:

$$
x_{i}(k+1)=x_{i}(k)+v_{i}(k+1)
$$

The final value of $x_{\text {gbest }}$ is regarded as the optimal solution of the problem.

\section{B. Mean-Variance Optimization (MVO)}

MVO is a new stochastic optimization algorithm [23]. MVO falls into the category of the so-called "populationbased stochastic optimization technique." The uniqueness of the MVO algorithm is based on the strategic transformation used for mutating the offspring based on mean-variance of the $n$-best dynamic population. The mapping function used transforms the uniformly distributed random variation into a new one characterized by the variance and mean of the $n$-best population attained so far. The searching space within the algorithm is restricted to the range - zero to one - which does not change after applying the transformation. Therefore the 
variables are treated always in this band but the function evaluation is carried out in the problem range. The features of MVO make it a potentially an attractive algorithm for solving many real-world optimization problems such as the tuning of PI controllers on a DFIG.

\section{Radial Basis Function Neural Network (RBFNN)}

The RBFNN in this paper is a three-layer feedforward neural network with the Gaussian density function as the activation function in the hidden layer [15]. The overall inputoutput mapping for the RBFNN, $\hat{f}: X \in R^{n} \rightarrow Y \in R^{m}$ is

$$
\hat{y}_{i}=b_{i}+\sum_{j=1}^{h} v_{j i} \exp \left(-\frac{\left\|x-C_{j}\right\|^{2}}{\beta_{j}^{2}}\right)
$$

where $x$ is the input vector, $C_{j} \in R^{n}$ is the center of the $j^{\text {th }} \mathrm{RBF}$ units in the hidden layer, $h$ is the number of RBF units, $b_{i}$ and $v_{j i}$ are the bias term and the weight between hidden and output layers respectively, and $\hat{y}_{i}$ is the $i^{\text {th }}$ output.

\section{Adaptive Critic Designs (ACDs)}

Adaptive critic designs [20], is a neural network-based optimization and control technique which solves the classical nonlinear optimal control problem by combining concepts of approximate dynamic programming and reinforcement learning. In dynamic programming, an optimal control is obtained by solving the Bellman equation that optimizes some cost-to-go function $J$ of the system, defined as:

$$
J(k)=\sum_{q=0}^{\infty} \gamma^{q} U(k+q)=\gamma J(k+1)+U(k)
$$

where $U(\cdot)$ is the utility function (user-defined function) which represents the one-stage cost of the system at each time step, and $\gamma$ is a discount factor $(0<\gamma<1)$.

The ACD method determines optimal control laws for a system by successively adapting two artificial neural networks (ANNs), namely, a critic network and an action network. The critic network learns to approximate the cost-to-go function $J(\cdot)$ in (4) and uses the output of the action network as one of its inputs, directly or indirectly; the action network provides the control action for the plant. The adaptation process starts with a nonoptimal control by the action network; the critic network then guides the action network towards the optimal solution at each successive adaptation. This adaptation uses the concept of reinforcement learning. During the adaptation, neither of the networks needs any information of the desired control trajectory, only the desired cost needs to be known. In

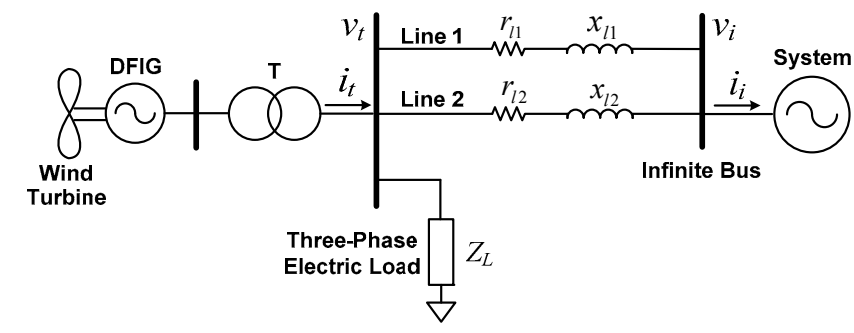

Fig. 3. Single-line diagram of a wind farm connected to a power network.
ACDs, a model network might be required to provide a dynamic plant model for training the critic and action networks.

Different types of critics have been proposed. A critic that approximates $J$ is called HDP; one that approximates the derivatives of $J$ with respect to its states is called DHP [20].

\section{Design of Optimal PI CONTROLlers For DFIG Wind TURBINES USING PSO AND MVO}

\section{A. PSO-Based Design Approach}

In the RSC control scheme (Fig. 2), there are four PI controllers. Each of them has a proportional gain and an integral time constant. In this section, the PSO algorithm is applied to find the optimal parameters of the four PI controllers, namely, four proportional gains $\left(K_{\omega}, K_{Q}, K_{d}\right.$, and $\left.K_{q}\right)$ and four integral time constants $\left(T_{\omega}, T_{Q}, T_{d}\right.$, and $\left.T_{q}\right)$, to optimize some performance measure function. Generally, the PI controller performance in the time domain can be measured by a set of parameters: the overshoot $M_{p}$, the rise time $t_{r}$, the settling time $t_{s}$, and the steady-state error $E_{s s}$. For example, if the objective is to minimize the over-current in the rotor circuit during grid faults, then a performance measure function can be defined as follows:

$$
f(x)=\beta \cdot \Delta I_{r, \max }+(1-\beta)\left(t_{s}-t_{0}\right)+\alpha \cdot\left|E_{s s}\right|
$$

where $x=\left[K_{\omega}, K_{Q}, K_{d}, K_{q}, T_{\omega}, T_{Q}, T_{d}, T_{q}\right]$ represents the position vector of each particle; $\beta$ and $\alpha$ are weighting factors; $\Delta I_{r, \max }$ is the maximum rotor current magnitude deviation of the DFIG; $t_{0}$ is the starting time of the disturbance.

The system in Fig. 3 is now considered. A large wind farm is connected to a power network through a step-up transformer and two parallel lines. The wind farm is represented by an aggregated model, in which over one hundred individual wind turbines and DFIGs are modeled as one equivalent DFIG driven by a single equivalent wind turbine, as shown in Fig. 1.

The PI controllers in Fig. 2 are initially designed (but not optimal) at a specific operating point. The parameters of the RSC controllers are then optimized at this operating point using PSO with 30 trial runs by applying a $100 \mathrm{~ms}$ three-phase short circuit at the receiving end of line 2. The initial values and the optimal values found by PSO for the RSC controller parameters are listed in Table I.

TABLE I

INITIAL AND OPTIMAL PARAMETERS OF THE RSC CONTROLLERS

\begin{tabular}{c|c|c|c|c|c|c|c|c}
\hline & $K_{\omega}$ & $K_{Q}$ & $K_{d}$ & $K_{q}$ & $T_{\omega}$ & $T_{Q}$ & $T_{d}$ & $T_{q}$ \\
\hline Initial design & 8.48 & 0.01 & 2.89 & 1.79 & 0.081 & 2.0 & 0.028 & 0.065 \\
\hline Optimal design & 18.23 & 0.001 & 3.05 & 4.87 & 0.038 & 1.0 & 0.056 & 0.21 \\
\hline
\end{tabular}

\section{B. PSO Simulation Results}

Different grid faults are applied to the power system in Fig. 3 to compare the performance of the optimal RSC controllers with that without the optimal design.

1) Case Study I: A $100 \mathrm{~ms}$ temporary three-phase short circuit is applied to the receiving end of line 2 at $t=5.0 \mathrm{~s}$. Fig. 4 shows the magnitudes of the DFIG rotor current for both 


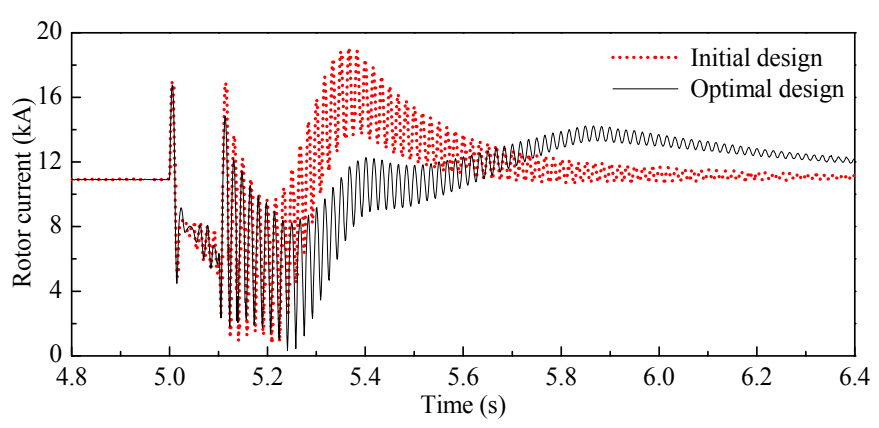

Fig. 4. Comparison of the initial design and the optimal design in Case I.

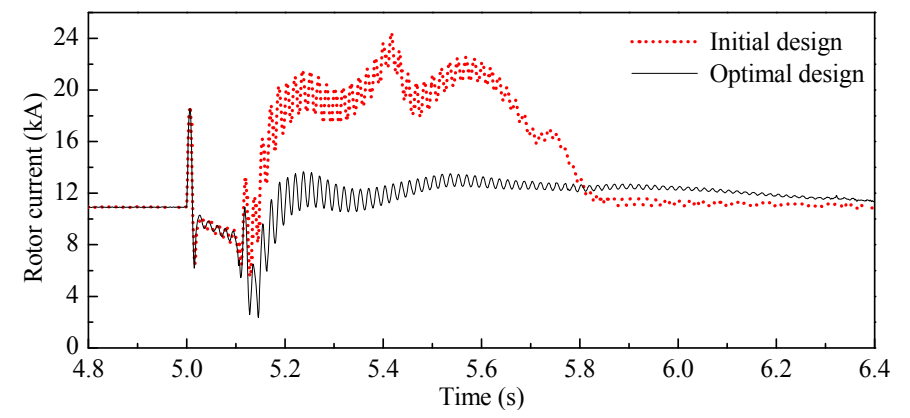

Fig.5. Comparison of the initial design and the optimal design in Case II.

designs. The rotor current peaks at only $14 \mathrm{kA}$ when applying the optimal design, which is much smaller than that of $19 \mathrm{kA}$ when using the initial design. The reduction of the overcurrent in the rotor circuit avoids the blocking of the RSC and therefore achieves continuous operation of the WTGS during this grid fault. Due to the stator flux oscillations during the transient state, the rotor current oscillates with a frequency near the synchronous frequency.

2) Case Study II: The two designs are compared for another case, in which a three-phase short circuit is applied to the sending end of line 2 and $100 \mathrm{~ms}$ thereafter line 2 is tripped off from the system. In this case, the system in Fig. 3 operates at a new operating point after the fault is cleared. Fig. 5 compares the magnitudes of the DFIG rotor current for both designs. Again, the magnitude of the post-fault rotor current peaks at only $13.5 \mathrm{kA}$ when applying the optimal design, which is much smaller than the peak post-fault rotor current when applying the initial design. It is concluded that the optimal design reduces the over-current in the rotor circuit effectively over a wide operating range.

\section{MVO-Based Design Approach}

Since the introduction of DFIGs for wind turbine generators, the technology of variable-speed wind turbines has been subjected to extensive research. However, with the variations in wind speed there is a change in the transient response of the Wind Turbine Generator System (WTGS). When a DFIG based WTGS is integrated to a multimachine power system consisting of SmartParks [24] (large number of plug-in electric vehicles in a parking lot) is subjected to severe disturbances, the resulting transients depending on the controller parameters can lead to a system collapse, especially when the wind power penetration is significant. When a fault is introduced, the variable-frequency converter (VFC) is the most susceptible part in the DFIG based wind generators. The VFC is controlled by a set of Proportional Integral (PI) controllers. The parameters of the PI controllers are very difficult to tune using traditional controllers due to the nonlinearity of the DFIG and increasing complexity of the smart grid. Therefore, there is need for the application of a heuristic method that is capable of intelligently tuning the PI controllers for the rotor-side converter (RSC) of the DFIG.

Reference [25] presents details on this study carried out on the real-time digital simulator (RTDS) using MVO to tune the PI controllers of the RSC of the DFIG in a multimachine power system with SmartParks. When three-Phase 10 cycle $(167 \mathrm{~ms})$ fault at the wind turbine generator bus, the optimization not only improves the stability of the DFIG at a wind speed of $13 \mathrm{~m} / \mathrm{s}$ system but also improves the stability of the other two generators in a 12 bus multimachine power system. Fig. 6 shows the speed of a generator with optimized and non optimized RSC PI controllers on the DFIG. With optimized parameters the speed of the generator settles down after fault introduction and hence the entire system is stable. However, with non optimized parameters, this is not the case. Similar results have been observed with wind speed fluctuations.

\section{HDP-BASEd COORdinating REACtive POWER CONTROL FOR A LARGE WIND FARM AND A STATCOM}

\section{A. Wind Farm, STATCOM and Power System Model}

The original 4-machine 12-bus benchmark power system in [21] is used as a platform system for studying FACTS device applications and integration of wind energy generation. Fig. 7 shows the single-line diagram of the extended 4-machine 12bus power system which now includes a large wind farm and a STATCOM. The system covers three geographical areas. Area 1 is predominantly a generation area with most of its generation coming from hydro power (G1 and G2). Area 2, located between the main generation area (Area 1) and the main load center (Area 3), has a large $400 \mathrm{MW}$ wind farm (G4). Area 3, situated about $500 \mathrm{~km}$ from Area 1, is a load center with some thermal generation (G3). The wind farm is

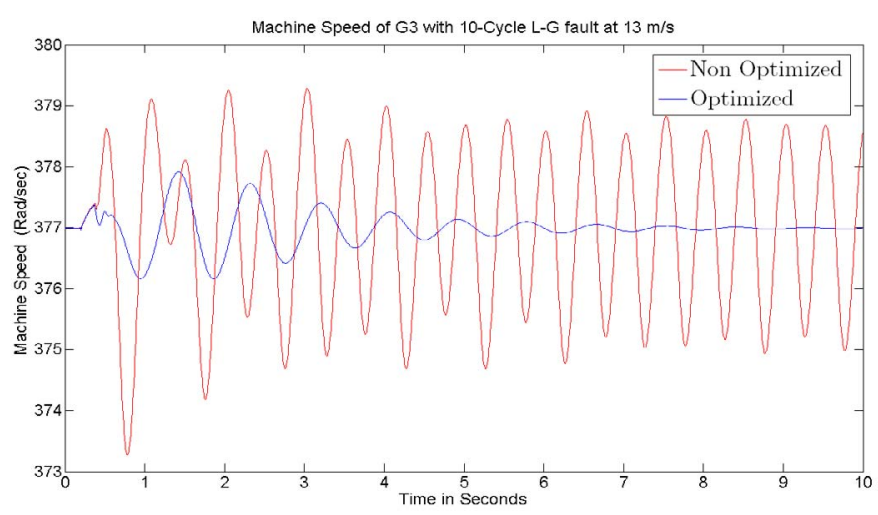

Fig. 6. Comparison of machine speeds $(\mathrm{rad} / \mathrm{sec})$ of a generator in the 12 bus system at wind speeds of $13 \mathrm{~m} / \mathrm{s}$ (left) with and without optimization after introduction of a 10 cycles $(166 \mathrm{~ms})$ three-phase fault. 


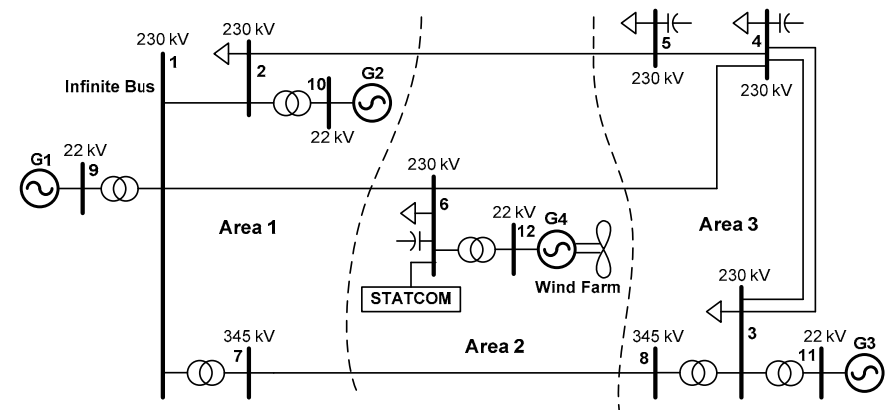

Fig. 7. Single-line diagram of the 4-machine 12-bus power system which includes a large wind farm and a STATCOM.

represented by an aggregated model as in Section IV. A STATCOM is placed at bus 6 to provide fast and smooth steady-state and transient voltage support for the wind farm.

\section{B. Design of the Interface Neurocontroller (INC)}

An ACD approach, the HDP, and RBFNNs are used to design an external interface controller for the coordinated reactive power control between the wind farm and the STATCOM, as shown in Fig. 8. The dashed line block denotes the plant to be controlled by the INC. The voltage deviation, $\Delta V_{6}$, at bus 6 and the active power deviation, $\Delta P_{g 4}$, of the wind farm are fed into the INC to produce two supplementary control signals, $\Delta Q_{s}$ and $\Delta Q_{C}$. They are then added to the steady-state fixed set-point values, $Q_{s 0}$ and $Q_{C 0}$, respectively, to form the total commanded values of the compensating reactive power, $Q_{s}{ }^{*}$ and $Q_{C}{ }^{*}$, at the input of the RSC and the STATCOM controllers. A basic principle is that by rapidly varying the amount of reactive power provided by the DFIG and the STATCOM during grid faults, it is possible to reduce the level of voltage sags at the PCC (bus 6 in Fig. 7) and therefore control directly the transient imbalances between the electrical output power $P_{g 4}$ and the mechanical input power that are responsible for over-current in the rotor circuit. Because of the direct coupling between voltage and reactive power, it is straight-forward to use the voltage deviation, $\Delta V_{6}$, as an input signal of the INC. In addition, the active power deviation $\Delta P_{g 4}$ contains the information of system oscillations and can therefore be used by the INC to damp power oscillations of the system.

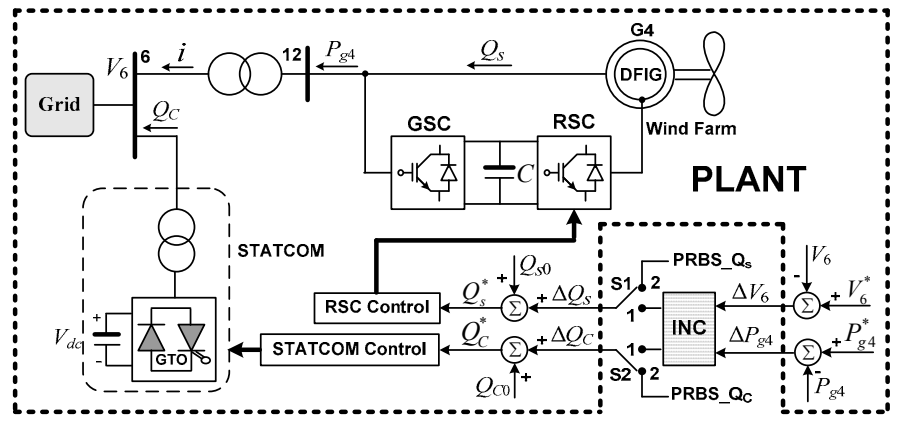

Fig. 8. Schematic diagram of the wind farm and STATCOM coordinated by an interface neurocontroller (INC).

\section{Simulation Results}

The wind farm initially operates at an operating point with DFIG rotor speed $\omega_{4}=1.2 \mathrm{pu}$, output active power $P_{g 4}=300$ MW, and output reactive power $Q_{g 4}=0$. The voltage at bus 6 is regulated at $V_{6}=1.02 \mathrm{pu}$. The compensated reactive power $Q_{C}$ of the STATCOM is limited to 250 MVar. A $150 \mathrm{~ms}$ temporary three-phase short circuit is applied to the bus 1 end of line 1-6 at $1 \mathrm{~s}$. The dynamic performance of the wind farm, reinforced with the INC, is compared to that without the INC.

Fig. 9 indicates that the maximum values of $Q_{C}$ are limited to 250 MVar for both cases with and without the INC. However, the post-fault power oscillations of $Q_{c}$ (Fig. 9) and $P_{g 4}$ (Fig. 10) in the case of the INC are damped more rapidly than for no INC. In addition, the peak value of the rotor current transient is reduced when using the INC, as shown in Fig. 11. These results confirm that the INC provides a smart coordinating control for the system. It improves the fault ridethrough capability of the wind farm and power oscillation damping of the system during this transient disturbance.

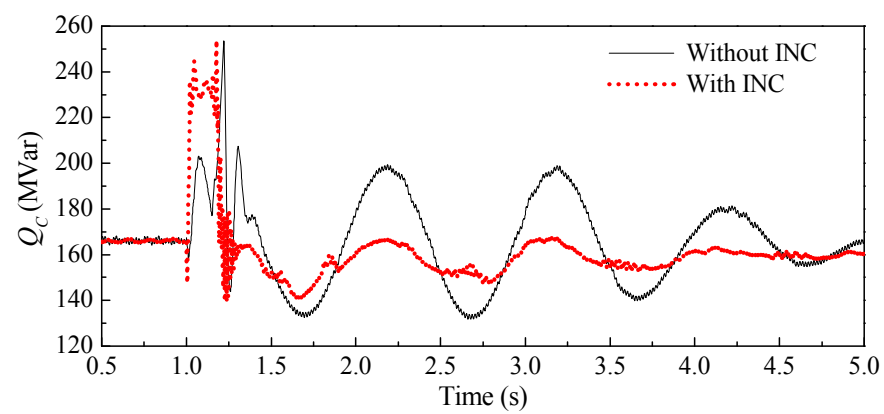

Fig. 9. Compensated reactive power by STATCOM with and without the INC.

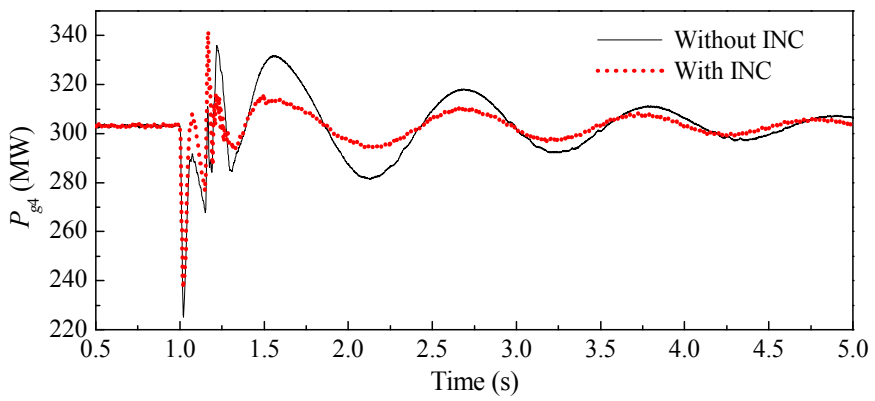

Fig. 10. Output active power of the wind farm with and without the INC.

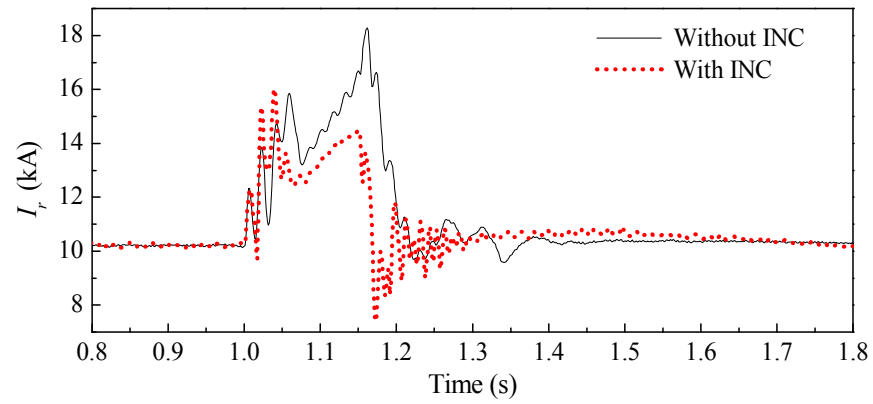

Fig. 11. DFIG rotor current with and without the INC. 


\section{CONCLUSION}

This paper has reviewed past and ongoing research in the application of CI techniques, e.g., PSO, MVO, fuzzy logics, neural networks, etc., for control of WTGs. Several intelligent design approaches and control strategies, including optimal design of WTG controllers using PSO and MVO algorithms and ACD-based coordinated optimal adaptive control for a wind plant and a STATCOM, have been presented. Nonrealand real-time simulations using PSCAD/EMTDC and RSCAD/RTDS have demonstrated the effectiveness of using these intelligent design approaches and control strategies for dynamic performance and fault ride-through enhancement of the WTGs. This paper has used DFIG wind turbines as an example to show the WTG control and integration improvement obtained from CI techniques. Similar approaches can be applied to other types of WTGs.

\section{REFERENCES}

[1] N. G. Hingorani and L. Gyugyi, Understanding FACTS: Concepts and Technology of Flexible AC Transmission Systems, New York: IEEE Press, 2000.

[2] V. Akhmatov, "Analysis of dynamic behavior of electric power dystems with large amount of wind power," Ph.D. dissertation, Technical University of Denmark, Kgs. Lyngby, Denmark, Apr. 2003.

[3] H. Li, K. Shi, and P. McLaren, "Neural-Network-Based Sensorless Maximum Wind Energy Capture With Compensated Power Coefficient," IEEE Trans. Ind. Appl., vol. 41, no. 6, pp. 1548-1556, Nov./Dec. 2005.

[4] W. Qiao, W. Zhou, J. M. Aller, and R. G. Harley, "Wind speed estimation based sensorless output maximization control for a wind turbine driving a DFIG," IEEE Trans. Power Electronics, vol. 23, no. 3, pp. 1156-1169, May 2008.

[5] W. Qiao, X. Gong, and L. Qu, "Output maximization control for DFIG wind turbines without using wind and shaft speed measurements," in Proc. IEEE Energy Conversion Congress and Exposition 2009, San Jose, CA, USA, Sept. 20-24, 2009, pp. 404-410.

[6] X. Yang, X. Gong, and W. Qiao, "Mechanical sensorless maximum power tracking control for direct-drive PMSG wind turbines," in Proc. IEEE Energy Conversion Congress and Exposition 2010, Atlanta, GA, USA, Sept. 12-16, 2010, pp. 4091-4098.

[7] M. Pucci and M. Cirrincione, "Neural MPPT Control of Wind Generators with Induction Machines without Speed Sensors," IEEE Trans. Ind. Electron., vol. 58, no. 1, pp. 37-47, Jan. 2011.

[8] V. Galdi, A. Piccolo, and P. Siano, "Designing an Adaptive Fuzzy Controller for Maximum Wind Energy Extraction," IEEE Trans. Energy Convers., vol. 23, no. 2, pp. 559-569, Jun. 2008.

[9] Q. Wang and L. Chang, "An intelligent maximum power extraction algorithm for inverter-based variable speed wind turbine systems," IEEE Trans. Power Electron., vol. 19, no. 5, pp. 1242-1249, Sept. 2004.

[10] W. Lin and C. Hong, "Intelligent approach to maximum power point tracking control strategy for variable-speed wind turbine generation system," Energy, vol. 35, no. 6, pp. 2440-2447, Jun. 2010.

[11] M. Simoes, B. Bose, and R. Spiegel, "Design and Performance Evaluation of a Fuzzy-Logic-Based Variable-Speed Wind Generation System," IEEE Trans. Ind. Appl., vol. 33, no. 4, pp. 956-965, Jul./Aug. 1997.

[12] M. Simoes, B. Bose, and R. Spiegel, "Fuzzy Logic Based Intelligent Control of a Variable Speed Cage Machine Wind Generation System," IEEE Trans. Power Electronics, vol. 12, no. 1, pp. 87-95, Jan. 1997.

[13] M. Mokadem, V. Courtecuisse, C. Saudemont, B. Robyns, and J. Deuse, "Fuzzy Logic Supervisor-Based Primary Frequency Control Experiments of a Variable-Speed Wind Generator," IEEE Trans. Power Syst., vol. 24, no. 1, pp. 407-417, Feb. 2009.

[14] W. Qiao, G. K. Venayagamoorthy, and R. G. Harley, "Design of optimal PI controllers for doubly fed induction generators driven by wind turbines using particle swarm optimization," in Proc. 2006 International Joint Conference on Neural Networks, pp. 1982-1986.
[15] W. Qiao, R. G. Harley, and G. K. Venayagamoorthy, "Coordinated reactive power control of a large wind farm and a STATCOM using heuristic dynamic programming," IEEE Trans. Energy Conversion, accepted for publication.

[16] W. Qiao, G. K. Venayagamoorthy, and R. G. Harley, "Real-time implementation of a STATCOM on a wind farm equipped with doubly fed induction generators," IEEE Trans. Industry Applications, vol. 45, no. 1, pp. 98-107, Jan./Feb. 2009.

[17] A. P. Engelbrecht, Computational Intelligence: an Introduction, New York: Wiley, 2007, pp. 4.

[18] J. Kennedy and R. C. Eberhart, "Particle swarm optimization," in Proc. of 1995 IEEE International Conference on Neural Networks, pp. 19421948.

[19] K. Alsabti, S. Ranka, and V. Singh, "An efficient k-means clustering algorithm," in Proc. First Workshop on High Performance Data Mining, Mar. 1998.

[20] D. V. Prokhorov and D. C. Wunsch, "Adaptive critic designs," IEEE Trans. Neural Networks, vol. 8, no. 5, pp. 997-1007, Sept. 1997.

[21] S. Jiang, U. D. Annakkage, and A. M. Gole, "A platform for validation of FACTS models," IEEE Trans. Power Delivery, vol. 21, no. 1, pp. 484-491, Jan. 2006.

[22] G. K. Venayagamoorthy, "A Successful Interdisciplinary Course on Computational Intelligence", IEEE Computational Intelligence Magazine - A special issue on Education, Vol. 4, No. 1, February 2009, pp. 14-23.

[23] I. Erlich, G. K. Venayagamoorthy and N. Worawat, "A Mean-Variance Optimization Algorithm" WCCI 2010 IEEE World Congress on Computational Intelligence, CCIB, Barcelona, Spain, July 18-23, 2010.

[24] P. Mitra and G. K. Venayagamoorthy, "Intelligent Coordinated Control of a Wind Farm and Distributed SmartParks," IEEE Industry Application Society Annual Meeting, Houston, TX, USA, October 3-7, 2010.

[25] P. Charkravarty and G. K. Venayagamoorthy, "Development of Optimal Controllers for a DFIG based Wind Generator in a Smart Grid under Variable Speed Conditions", in Proc. of 2011 IEEE International Electric Machines and Drives Conference. 